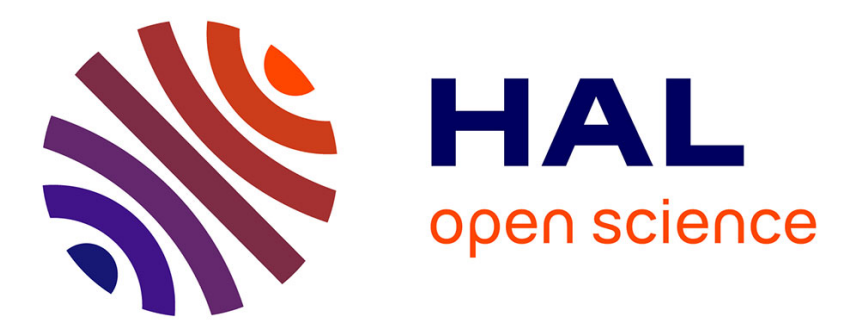

\title{
A Crucial Role of Attention in Lateralisation of Sound Processing?
}

Martine Hausberger, Hugo Cousillas, Anaïke Meter, Genta Karino, Isabelle

George, Alban Lemasson, Catherine Blois-Heulin

\section{To cite this version:}

Martine Hausberger, Hugo Cousillas, Anaïke Meter, Genta Karino, Isabelle George, et al.. A Crucial Role of Attention in Lateralisation of Sound Processing?. Left Versus Right Asymmetries of Brain and Behaviour, MDPI, pp.43-63, 2019, Symmetry, 978-3-03921-692-5. 10.3390/books978-3-03921-693-2 . hal-02417828

\section{HAL Id: hal-02417828 \\ https://hal-univ-rennes1.archives-ouvertes.fr/hal-02417828}

Submitted on 22 Sep 2020

HAL is a multi-disciplinary open access archive for the deposit and dissemination of scientific research documents, whether they are published or not. The documents may come from teaching and research institutions in France or abroad, or from public or private research centers.
L'archive ouverte pluridisciplinaire HAL, est destinée au dépôt et à la diffusion de documents scientifiques de niveau recherche, publiés ou non, émanant des établissements d'enseignement et de recherche français ou étrangers, des laboratoires publics ou privés. 


\title{
Article \\ A Crucial Role of Attention in Lateralisation of Sound Processing?
}

\author{
Martine Hausberger ${ }^{1}$, Hugo Cousillas ${ }^{1}$, Anaïke Meter ${ }^{2}$, Genta Karino ${ }^{3}$, Isabelle George ${ }^{1}$, \\ Alban Lemasson ${ }^{2}$ and Catherine Blois-Heulin ${ }^{2, *}$ \\ 1 C.N.R.S., Ethologie animale et humaine EthoS, UMR 6552, Université de Rennes, Université Caen \\ Normandie, Campus de Beaulieu, B25, Avenue du Général Leclerc, 35000 Rennes, France; \\ martine.hausberger@univ-rennes1.fr (M.H.); hugo.cousillas@univ-rennes1.fr (H.C.); \\ isabelle.george@univ-rennes1.fr (I.G.) \\ 2 C.N.R.S., Ethologie animale et humaine EthoS, UMR 6552, Université de Rennes, Université Caen \\ Normandie, Station Biologique, 35380 Paimpont, France; annick.meter@univ-rennes1.fr (A.M.); \\ alban.lemasson@univ-rennes1.fr (A.L.) \\ 3 Department of Biotechnology and Life Science, Graduate School of Engineering, Tokyo University of \\ Agriculture and Technology, 2-24-16 Naka-cho, Koganei-shi, Tokyo 184-8588, Japan; \\ gentachan2011@gmail.com \\ * Correspondence: catherine.blois-heulin@univ-rennes1.fr; Tel.: +33-299-61-81-65, Fax: +33-299-61-81-88
}

Received: 22 November 2018; Accepted: 24 December 2018; Published: 3 January 2019

\begin{abstract}
Studies on auditory laterality have revealed asymmetries for processing, particularly species-specific signals, in vertebrates and that each hemisphere may process different features according to their functional "value". Processing of novel, intense emotion-inducing or finer individual features may require attention and we hypothesised that the "functional pertinence" of the stimuli may be modulating attentional processes and hence lateralisation of sound processing. Behavioural measures in "(food) distracted" captive Campbell's monkeys and electrophysiological recordings in anesthetised (versus awake) European starlings were performed during the broadcast of auditory stimuli with different functional "saliences" (e.g., familiar/novel). In Campbell's monkeys, only novel sounds elicited lateralised responses, with a right hemisphere preference. Unfamiliar sounds elicited more head movements, reflecting enhanced attention, whereas familiar (usual in the home environment) sounds elicited few responses, and thus might not be arousing enough to stimulate attention. In starlings, in field L, when awake, individual identity was processed more in the right hemisphere, whereas, when anaesthetised, the left hemisphere was more involved in processing potentially socially meaningless sounds. These results suggest that the attention-getting property of stimuli may be an adapted concept for explaining hemispheric auditory specialisation. An attention-based model may reconcile the different existing hypotheses of a Right Hemisphere-arousal/intensity or individual based lateralisation.
\end{abstract}

Keywords: hemispheric specialisation; attention; starlings; Campbell's monkeys; auditory perception

\section{Introduction}

At the time of and also because of Broca's (1861) [1] early findings of a dominance of the left hemisphere for language production and processing, brain lateralisation has long been considered a unique human feature. Only in the last decades have parallels been sought and found in animals, revealing that brain lateralisation is a rather universal feature amongst vertebrates and some invertebrates [2-5]. Surprisingly, auditory laterality is amongst the latest studied aspects, but these studies have shown that there are clear asymmetries for processing, in particular species-specific sound signals, in vertebrates [6-9]. Most of these studies have investigated whether animals, as a parallel to 
language processing, had a dominant hemisphere for the processing of the species-specific vocalisations. Indeed, a left dominance for species-specific vocalisations has been found in a series of species such as seals [10], mice [11], raptors [12], cats [13], rhesus macaques [14,15], and chimpanzees [16] using ear orientation in response to playbacks or lesional approaches such as Heffner and Heffner $[17,18]$. However, results in songbirds and some primate species are more mitigated: lesions, electrophysiological and/or behavioural tests reveal a left dominance in Bengalese finches [19], rhesus macaques [20] but a right dominance in zebra finches [21], European starlings [22,23], vervet monkeys [24] and Japanese macaques [25] in response to species-specific vocal signals. When investigating further, however, both Cynx et al. [21] and George [22,23] found a more complex process as each hemisphere seemed to process different features even within the species-specific songs according to their social (e.g., individual) or functional (familiar/nonfamiliar) "value".

This reminds one of the processing of other important features of speech such as prosody and emotional content that are processed in the right hemisphere by humans [26]. These features are important for a listener to appreciate the emitter's identity, intentions and attitudes [27].

It has been proposed that, in birds, the right hemisphere would be more involved in finer discriminations [21] or responses to novel features [28], a parallel with baboons or gray mouse lemurs where it has been suggested that non-familiar sounds are processed in this hemisphere $[29,30]$ although recent findings show that familiar stimuli are processed more in this hemisphere in Japanese macaques [25]. In Campbell's monkeys confronted by species-specific and heterospecific social calls with different emotional valences, only the species-specific calls with a negative valence elicited a lateralised response with a preference for the right hemisphere (left head turning) [31], as also observed in Emei music frogs [32]. Sex differences may occur as in mouse lemurs, for example, a species where males, but not females, exhibit a significant right ear-left hemisphere bias when exposed to conspecific communication sounds of negative emotional valence [33]. Interestingly, these laterality biases may extend to interspecific perception: in dogs, the right hemisphere dominance for conspecific barks extends to the signals of another (familiar) species, cats, while human orders are processed without any hemispheric preference [34]; in cats, the left hemisphere is more involved in the processing of species-typical vocalisations such as meow or purring, but not for growling, while sounds eliciting intense emotions (dogs' vocalisations of "disturbance") are associated with the right hemisphere [13].

In any case, finer discriminations and processing of novel or intense emotion-inducing features may require more attention, which is considered as one basis for the evolution of lateralisation [35]. Female free-ranging orcas, but not males, show a significant preference for the use of the left eye when looking at humans, which can be associated with their higher sustained visual attention towards humans [36]. It was proposed that the two hemispheres did not have a similar function: focused attention will be processed by left hemisphere and conversely broad attention by right hemisphere [37].

While most studies involve behavioural responses (i.e., eye or ear/head turning) as indirect information of brain lateralised processing, some electrophysiological studies suggest further a link between perceptual laterality and attention. Thus, in European starlings, an auditory dominance can only be observed in awake birds and not in anaesthetised birds, but also the types of sounds processed by the two hemispheres differ between the two states [22,23,38].

More recently, an EEG study on horses has revealed that processing of visual attention per se is lateralised, with a clear predominant involvement of the right hemisphere [39].

The aim of the present study was therefore to investigate this mutual relationship between attention and lateralisation, by looking at auditory perception in two species of primates and songbirds, the Campbell's monkeys and the European starlings, both known to perceive and process species-specific stimuli at least with lateralised responses (e.g., [22,23,31,40]). On the other hand, both species show different levels of attention and auditory response according to the social familiarity or social functional significance of the stimuli: in Campbell's monkeys, old (no longer used) but familiar variants of contact calls [41] or unexpected types of vocal interactions [42] elicit a cessation of activity and visual attention. Female starlings respond to the playback of familiar shared songs with 
visual search [43], and familiarity was a major modulation factor in auditory responses in the field L of adult male starlings [44].

We hypothesised therefore that the "functional pertinence" of the stimuli may be modulating attentional processes (see also the "attention neurons" proposed by Hubel et al. [45]) and hence lateralisation of the sound processing, while attentional processes per se would modulate responses. While we expect more functionally salient stimuli (e.g., social calls) to be triggering more attention and enhanced lateralisation, manipulating attention should change those responses. To test this hypothesis, we used behavioural tests in Campbell's monkeys and electrophysiological recordings in European starlings to investigate the impact of attention on the lateralisation of neuronal or behavioural responses to the broadcast of auditory stimuli with different functional "saliences" (familiar/novel, species-specific/non-specific, etc.). In both species, only females were tested. In European starlings, data on male lateralisation of sound processing were already known $[22,23,46]$ and could be used for comparison. In Campbell's monkeys, females are at the core of the social network, with clear individualised bonds $[47,48]$, and therefore appeared as interesting to test. We manipulated the attention of the animals in two ways: by adding a (food) distractor to the monkeys, as we expected them to then pay attention only to particularly salient stimuli and by looking at neuronal responses in the primary auditory area of anaesthetised animals in starlings, an extreme case of loss of attention. In Campbell's monkeys, novel and familiar species-specific and non-specific sounds (other species present or not in the environment, and non-biological sounds) were used as we expected the monkeys to respond less to sounds usually heard in their environment (e.g., horses [49]). We hypothesised that, more than a mere dominance of a hemisphere for species-specific sounds, a more subtle specialisation may be found according to the "attentional value" (e.g., "novelty") of the sound for the animal. We chose to broadcast the full series of sounds to each individual, a procedure that has proved useful in birds and may avoid controversies related to the playback of only one sound to one animal $[14,50,51]$. We also expected unfamiliar and familiar sounds to elicit different levels of arousal/attention that might reflect the level of reaction to the playback in terms of number of reactions and strength of orientation.

\section{Results}

\subsection{Study 1: Behavioural Responses of Campbell's Monkeys to Familiar or Novel Sound Stimuli}

This study was performed on six captive born female Campbell's monkeys, aged 4-13 years, and living in the same social group. The distractor was a homemade caramel, which was spread on the wire net inside the room just above a metal tray on which the monkeys could sit in order to lick it. This food element proved very attractive as all animals remained sitting on the tray during the whole experiment, licking it actively. Nine distinct sound categories were used that were or were not familiar or close in structure to the own species calls. These nine sound categories were: white noise (non-biological stimulus), vocalisations of familiar (conspecifics) primates and birds, and of unfamiliar male and female primates and birds. All sounds were calls with a social positive valence (for the concerned species). The term familiarity was used here as "common in the environment" and not in terms of "individual familiarity". A total of 540 playbacks were performed with 90 sounds per female ( 5 exemplars of 8 biological sounds $\times 2+10$ times white noise). The analysis of the video recordings revealed head movements and orientations in response to playbacks that occurred within the second following the playback. Therefore, only changes in behaviour occurring in the second following playback were considered as responses.

\subsubsection{Results of Study 1}

Overall, a high proportion of the playbacks elicited a clear response (314 out of 540 tests, binomial test response/no response: $p=0.0002$ ). No habituation could be detected as the proportion of playback eliciting a response did not differ between both sessions (Wilcoxon test, $p>0.05$ in all cases) or 
according to the rendition order for white noise (Spearman rank order correlation, $\mathrm{N}=10, \mathrm{r}=-0.298$, $p=0.4)$.

Three stimuli elicited clearly a higher proportion of responses than the others: the loud calls of the male Wolf's monkeys (63\%: binomial test: $p=0.05)$, the social calls of the females Wolf's monkeys $(80 \%: p=0.0006)$ and the barnacle goose calls $(80 \%: p=0.0006)$. The most familiar sounds appeared to elicit the lowest level of response (51\% for the female Campbell's monkey calls and $40 \%$ for the European starling whistles) $(p<0.26)$.

When considering individual responses in terms of lateralisation, clear differences according to stimulus were observed in the second session (Figure 1), while none was found for the first session (Wilcoxon tests, $\mathrm{N}=6, p<0.11$ ). All subjects turned their heads significantly to the left after hearing four unfamiliar stimuli: social calls of female baboons ( $87 \%$ of the responses) and of female Wolf's monkeys $(84 \%)$ and barnacle goose vocalisations $(80 \%)$ and white noise $(69 \%)$ (Wilcoxon tests, $\mathrm{N}=6, p<0.04)$. No significant right/left differences were found for any of the familiar stimuli, or the species-specific calls (unfamiliar in terms of individual identity but familiar in terms of overall structure: $56 \%$ for male and 53\% for female Campbell's monkeys' calls elicited orientations to the right).

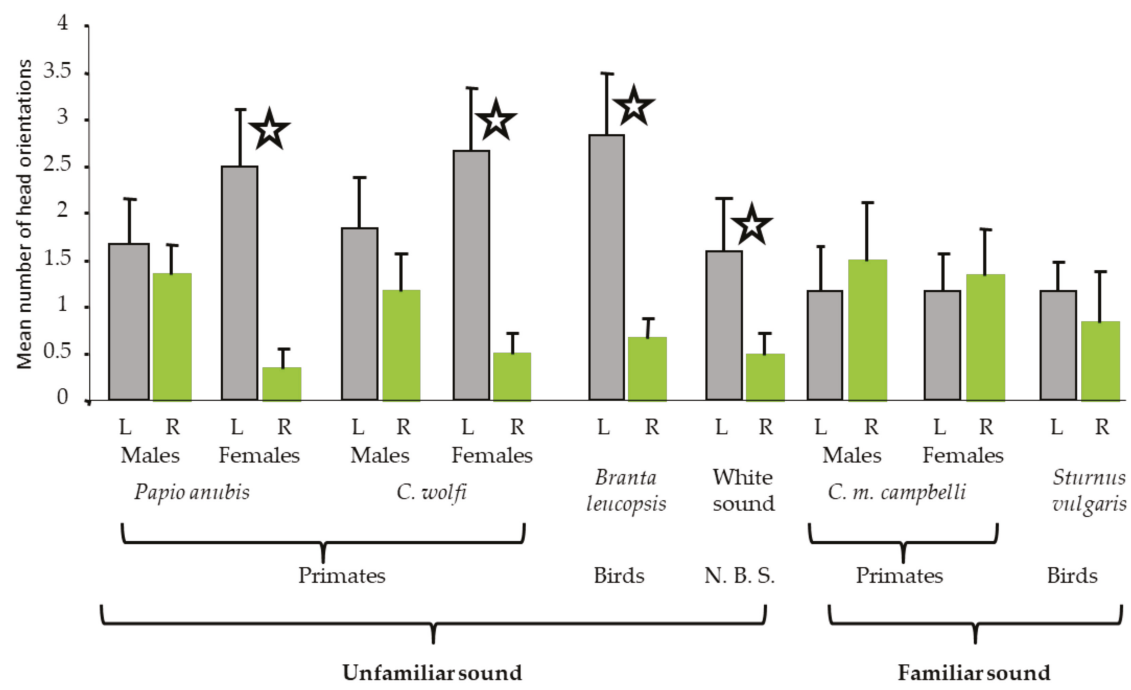

Figure 1. Variation of the mean (+/ - s.e.) number of head orientations according to stimuli, calculated from all subjects. L: left orientation, R: right orientation, N.B.S.: Non-Biological Sound, Star: significant difference - Wilcoxon tests.

\subsubsection{Discussion of Study 1}

The broadcast of a series of sounds varying in terms of familiarity and while the animals had a food distractor showed that only novel sounds elicited responses above chance level, and most of all lateralised responses, with a right hemisphere preference. Familiar sounds, either because they were species-specific or because the species concerned were common in the environment, elicited few responses and no lateralisation. The animals' responses suggest that species-specific calls and sounds of another non-primate species common in the environment might all correspond to a same general "familiar" category, that, when animals are occupied by another preferred activity may not create enough arousal to stimulate attention. Hearing familiar sounds while focusing on an attractive "task" may not elicit arousal. Unfamiliar sounds on the other hand elicited more responses in terms of head movements, suggesting that the animals paid more attention. Another element is that these unfamiliar sounds elicited the same level of responses in the two sessions, whereas lateralisation of the responses became clear only at the second session, as if a certain level (or an increased level) of attention was 
necessary in order to adapt their responses. Both a probable decrease of motivation elicited by the caramel and the repetition of unfamiliar sounds could explain increased attention. In the present study, the unfamiliar sounds may have been "startling" enough to distract the monkeys from their focus on the caramel.

In another study with also a food distractor, the Campbell's monkeys confronted by familiar (group members) species-specific calls elicited lateralised responses (left head turning, right hemisphere) only when they had a negative valence (i.e., threat calls, and not for contact calls) [31]. This actually may reinforce a potential role of attention; as such signals do require an immediate arousal and readiness to respond, contrary to social positive signals. Indeed, in this same study, as in the present one, neither heterospecific calls nor social positive species-specific calls elicited any lateralised response.

The social function of the vocalisation and the subsequent attention of the female must also be taken into account. No lateralised responses to male loud calls were observed in the present study with a food distractor, whatever the familiarity level. Campbell's monkeys present strong vocal and sexual dimorphisms. Male loud calls are directed toward other males in a competitive context (or in alarm contexts, [52]) and females react much less to the loud calls of other conspecific males than to those of their harem male, which may explain why they showed no laterality for any of the male loud calls broadcasted. On the contrary, female contact calls are involved in pacifying interactions and, through vocal convergence, reflect social affinities $[47,53]$. In horses, lower responses and no lateralised head turning was observed when they heard the whinnies of group members in their familiar setting [54].

\subsection{Study 2: Electrophysiological Responses of Auditory Neurons to Different Sounds in European Starlings}

Twenty-six wild-caught adult female European starlings were used for this study. Ten were recorded while awake-restrained, and 16 while anesthetised both during and outside the breeding season. Auditory stimuli consisted in artificial non-specific sounds and songs chosen for their behavioural relevance: Class-I: species-specific whistles that are common to all males and are the bases for male-male interactions and dialectal variations; Class-II whistles that are more individual-specific but can be shared by close social (same sex) partners; and Class-III warbling motifs that are individual specific but can be shared by close social partners excepted for clicks, common in all male songs all year round and high-pitched trills that occur at the end of the warbling sequence and are more frequent at breeding time and especially in unmated males (see Section 4.2.).

\subsubsection{Results of Study 2}

Since there were no significant differences in terms of laterality between the recordings performed during or outside the breeding period within each category of bird (awake/anaesthetised), data were pooled. There were more neuronal responses to the auditory stimuli overall when the birds were awake than when they were anaesthetised [38].

A clear laterality of sound processing appeared in the awake-restrained birds, revealing that the individual song elements from a known bird (group member) elicited more responses in the right hemisphere (Wilcoxon test, $\mathrm{N}=10, \mathrm{Z}=2.54, p=0.01$ ) while the more universal motif types (clicks and high pitched trills) elicited more responses in the left hemisphere (Wilcoxon test, $Z=1.9, p=0.05$ ). The artificial sounds and male-specific universal species-specific Class I whistles did not elicit any lateralised response (Figure 2).

The pattern was clearly different in the anesthetised birds, which showed no lateralisation for individual songs but a left hemisphere dominance for the artificial sounds and again for the more universal features of Class III songs (Wilcoxon tests, artificial sounds, $Z=1.96 p=0.049$; clicks and trills $Z=2.52, p=0.01$ ). 


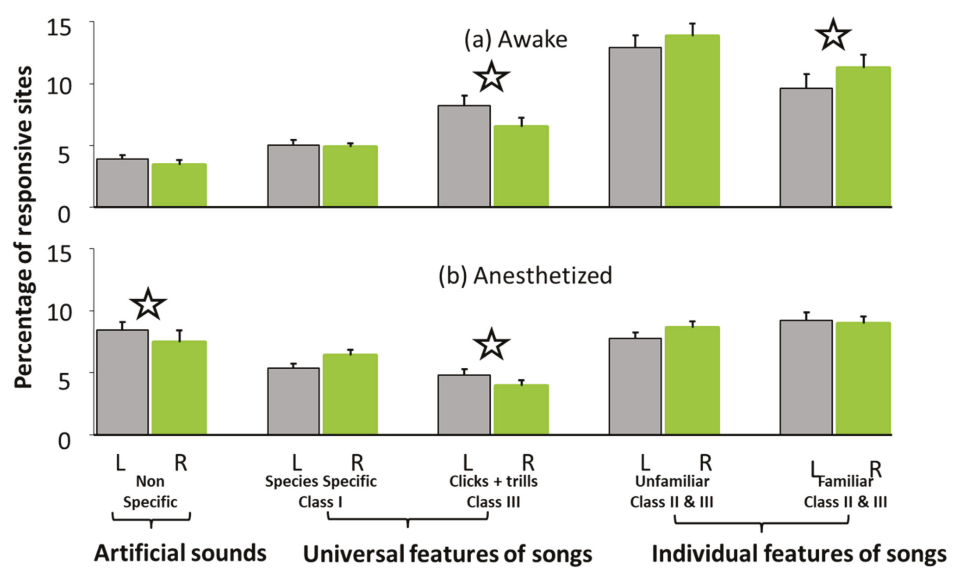

Figure 2. Laterality of neuronal preferences (\%: percentage of responsive sites) in field L of awake (a) and anaesthetized (b) European Starling: percentage of neural sites that responded to nonspecific (artificial sounds), universal features of songs (species specific Class I, Class II clicks and trills) and familiar and unfamiliar individual songs (Class II whistles and Class III motifs).

\subsubsection{Discussion of Study 2}

The neuronal responses in field $\mathrm{L}$ of adult female starlings clearly differed according to the birds' wakefulness state, with more responses in the right hemisphere for a familiar bird (group member) when they were awake, a lateralised response that disappeared when they were anaesthetised. They also showed more responses towards artificial sounds when anaesthetised, these elements, similar to the more universal warbling motifs, being processed most in the left hemisphere. Interestingly, fRMI studies on anaesthetised females showed the same preference of Right Hemisphere (RH) for processing individual songs from unknown males and Left Hemisphere (LH) for the universal species-specific song elements [40].

These results differ to some degree from those obtained in male starlings [22]: in awake birds, there was an overall predominance of $\mathrm{RH}$ responses that we did not particularly observe in females, and the RH was more involved in processing individual songs, whether familiar or unknown. In anaesthetised birds, RH was involved in processing universal species-specific sounds while they were processed on the left in females. Such sex differences may be due to either a differential general laterality of sound processing in males and females or the fact that only male songs were broadcasted in both cases, which means they did not have the same social significance for both types of birds. Further studies involving female song should be performed.

In both sexes though, when animals are awake, individual identity is processed more in the right hemisphere while, when anaesthetised, the left hemisphere seems to be more involved in processing potentially socially meaningless sounds such as artificial sounds as is the case in anaesthetised adult female zebra finches, which also have artificial sounds processed in LH [55].

These results reinforce the idea that the right hemisphere would be more involved in processing individual information as suggested by different studies on chickens [56,57], quails [58] or sheep [59].

\section{General Discussion}

The results obtained on both species studied here with different paradigms (head orientation versus electrophysiological recordings) converge in showing that altered attention, either by having a distractor or through anaesthesia, leads to particular lateralised patterns of response. In the two studies using food distractor, female Campbell's monkeys, confronted by negative and positive social calls produced by conspecifics or familiar other primates, show a right hemisphere dominance for only 
the negatively connoted species-specific calls [31], while they also show a right hemisphere dominance for all sorts (heterospecific, artificial sounds) of novel sounds and lower non-lateralised responses for familiar sounds (including positively connoted species-specific calls).

When female starlings are awake, there is a right dominance of the Field L neurons for individual familiar songs, while, when they are anaesthetised, this dominance disappears, with LH processing potentially more meaningless sounds.

Interestingly, differences in laterality of responses in distracted animals (juice drink during playback) were also observed in two studies using two different "types of familiarity" procedures on mouse lemurs: while the authors found a LH bias for conspecific calls with a negative valence recorded in the field [33], they found no such bias according to call valence in another study where the calls were recorded from non-group members living in the same facility [30].

In the latter case, they did not find any bias for familiarity, contrary to our primate study, but they used calls from animals that were not group members but still present in the facility. Horses react to the whinnies of neighbouring (non-group members) horses as familiar compared to those produced by totally unknown horses $[49,54]$. Therefore, the question remains open as how the lemurs would have processed familiarity if really unknown calls had been broadcasted. Future studies on diverse species should probably differentiate between individual familiarity and sound familiarity, in terms of acoustic environment or structural proximity.

However, while in our studies both species revealed a clear influence of the attentional state on the pattern of laterality observed, they also showed apparent discrepancies. Thus, there was a RH bias for processing negatively connoted species-specific calls in distracted Campbell's monkeys, whereas RH was more involved in processing familiar rather neutral or positive familiar songs in awake starlings. In addition, while only novel (i.e., unfamiliar) sounds, whether heterospecific or artificial, elicited higher and lateralised RH responses in distracted Campbell's monkeys, starlings' neurons reacted to these sounds with a LH dominance.

This suggests that brain processing of auditory stimuli and the associated emotional valence differs between these species, that distraction and anaesthesia certainly do not represent the same level of attention alteration, or that there is another common process that may explain these discrepancies. Overall, all EEG studies converge to indicate a LH bias for positive and RH bias for negative emotional states in human studies including when processing speech, as also shown in most animal studies using visual stimuli (i.e., [58,60-64]). Animal behavioural studies on auditory perception are not as clear-cut: dogs turn more the head towards the left $(\mathrm{RH})$ when hearing a thunderstorm noise or human voices with a negative valence $[65,66]$, as do Campbell's for conspecific calls with a negative valence [31] but mouse lemurs turn more the head towards the right (LH) for the same type of stimulus [33]. In addition, domestic goats show more right head turning (LH) for conspecific calls produced in supposedly negative contexts (isolation, frustration, dog barks) but also for calls produced in anticipation of feeding, a context supposedly associated with positive emotions [67]. The authors concluded that the RH processes high arousal independently of valence, although one alternative possibility is that anticipation of positive event may correspond to a quite ambiguous situation [68]. Following Baciadonna et al. [67], one hypothesis therefore would be that lateralised processes concern intensity and not valence of the stimuli, two aspects of emotions separated in the circumplex model of Lang et al. [69]. This would be in contrast to the valence theory [70] that predicts a clear impact of valence on the lateralisation of stimulus processing (see also [71,72]).

How can we explain the number of studies, including the present one, showing that individual identity, familiarity and overall functionally significant stimuli are processed with hemispheric specialisation, without any particular arousal? In dogs, fMRI studies indicate that meaningful (human) auditory stimuli are processed on the right side, while "marked" words are processed in LH [73], and behavioural studies that a "positive" human voice is processed in RH in this species [74].

Actually, there is only one way of explaining these different facets of laterality which is, as suggested by Andrew [75], attention. If, as suggested by different authors, the right hemisphere 
is more involved in detailed analysis (which requires attention) (e.g., [8]), then it could explain why in awake undistracted animals, it is devoted to the analysis of individual identity (e.g., [76]), in both distracted and undistracted animals to negatively connoted stimuli, that tend to attract more attention [77-80] and anticipatory contexts where the animals' attention is focused on expectation. For example, dogs processed "happy" human voices with the LH, but they also showed a lower arousal for these voices than those reflecting fear [66]. There is more activation of RH when humans watch incongruent audio-visual interactions on videos [81], and incongruence is known to stimulate attention [82]. Alertness overall tends to increase for both salient or more negative interpersonal conditions [83], which leads one to consider that the arousal elicited by auditory stimuli is more important than their specific valence. However, arousal involves attention.

When distracted by an appealing food, female Campbell's monkeys just reacted to novel and thus "incongruent" (no baboon or barnacle geese in their captive environment) sounds with left head turning (RH): familiar sounds such as contact calls of conspecifics or birds (starlings) common in their environment obviously were not salient enough to trigger reactions, and still less so laterality. Auditory neurons of male and female anaesthetised starlings showed responses to meaningless sounds, such as artificial sounds, mostly in the left hemisphere, as also observed in female zebra finches [55].

Awake female starlings showed a RH bias for particularly meaningful conspecific calls, such as the individual songs of known birds (which reflect social bonding, [43]) and distracted female Campbell's monkeys also showed a RH bias for negatively connoted calls of conspecifics [31]). One can think that the salience of the stimuli depends on the functional significance of the signals for each species. According to Syka et al. [84] and Huez et al. [85], in mammals, anaesthesia affects sensory elements that show relevance, and attention is required for processing meaningful vocalisations.

If, as proposed by Andrew and Watkins [35], we consider attention as a core aspect of hemispheric specialisation, then it would explain enhanced laterality for novelty, incongruence, and highly (e.g., socially) significant signals, as well as discrepancies between studies using (e.g., [30,65]) or not (e.g., [74]) a food distractor. Distraction may raise the threshold of attention-getting value of the stimuli and thus alter laterality.

Electrophysiological data converge to suggest a higher implication of $\mathrm{RH}$ in attentional processes in humans [82,86] and horses [39]. Meaningful sounds elicit more responses in the RH of dogs $[73,87,88]$.

In the same line, Ghazanfar et al. [20] showed that rhesus monkeys oriented to the left for reversed calls, which may have been perceived as incongruent hence deserving further attention. Pohl [29] argued that the right hemisphere in baboons processes pure tones, musical sounds and vowels and he suggested that processing these unfamiliar structures is more difficult. Cynx et al. [21] and Watkins [28] proposed that the RH played a similar role in processing novel features or more complex sounds. Thus, hens' clucks are processed in the left hemisphere, but the introduction of a new note (novel feature in a familiar sound) induces processing in the right hemisphere [28].

Our results suggest, for the first time, that the attention-getting property of stimuli may be a more adapted concept for explaining hemispheric auditory specialisation (including also the species-specific vocalisations) and may explain that the distinction between familiar/novel may be more important than between species-specific versus non-specific stimuli. Thus, in our study on monkeys, the responses were clearly oriented towards the left (RH) for an unfamiliar bird (barnacle goose), whereas there was no clear orientation for another bird, the European starling, common in the animal's environment. Horses show no lateralised responses when hearing the whinnies of a group member within the familiar pasture but react with a lateralised pattern when hearing a total stranger or a familiar non-group member horse that never shares the same pasture [54].

An attention-based model may reconcile the different existing dominant hypotheses of a RH- [70,88-92], arousal/intensity or individual [56] based lateralisation, in particular for auditory perception. According to a species' social organisation/structure or life conditions, the more meaningful, hence attention-getting stimuli, may differ. 


\section{Materials and Methods}

\subsection{Study 1: Behavioural Responses of Campbell's Monkeys to Familiar or Novel Sound Stimuli}

\subsubsection{Subjects}

This study was performed on six captive born female Campbell's monkeys, aged 4-13 years, and living in the same social group, composed of one adult male, six adult females and three juveniles (one male and two females) at the time of the experiment. The animals were housed in an enclosure divided into outdoor $\left(21 \mathrm{~m}^{2} \times 4 \mathrm{~m}\right)$ and indoor $\left(21 \mathrm{~m}^{2} \times 3 \mathrm{~m}\right)$ parts. Trap doors enabled the animals to move freely from one to the other part. However, during the playback sessions, they were kept indoors.

\subsubsection{Procedure}

The indoor part was connected to the experimental room through a trap door and a concrete wall separated both rooms. Therefore, when in the experimental room, the animals could hear but not see the rest of the group. The monkeys were trained to leave the group in order to go individually to the experimental room using food reinforcement several weeks before the onset of the experiments. The six females would go easily and did not show any sign of stress during the experiments.

The distractor was a homemade caramel, which was spread on the wire net inside the room just above a metal tray $(20 \mathrm{~cm} \times 20 \mathrm{~cm})$ on which the monkeys could sit in order to lick it. This food element proved very attractive as all animals remained sitting on the tray during the whole experiment, licking it actively. This also ensured that during the experiments the animals would keep quietly sitting with their back towards the loudspeaker in a symmetrical position. Playbacks only occurred when the animal was in this position, licking the caramel. A video camera was placed in front of the animal in order to record its behaviour.

The experiment took place between 26 March and 25 April 2005. Two experiments were performed per day: one before food distribution in the morning and the other in the afternoon. The animals were tested individually in a rotating order and, to avoid habituation and/or loss of motivation in the situation, only two sounds were broadcast per day for a given female. Playback was manually ordered through a computer (Amiga- Commodore - U.S.A.) by the experimenter, who waited for the animal to be sitting with its ears symmetrical to the loudspeaker before starting the playback. The interval between two successive sounds was therefore variable (1-10 $\mathrm{min}$ ) depending on the behaviour of the subject. After the first sound, the subject had to move away from the caramel and then to place itself again in front of the caramel.

\subsubsection{Auditory Stimuli}

Nine distinct sound categories were used that were or were not familiar or close in structure to the own species calls. These nine sound categories were: white noise (non-biological stimulus), vocalisations of familiar male and female primates, Campbell's monkeys (C. c. campbelli), familiar birds, European starlings (Sturnus vulgaris), unfamiliar male and female primates, baboons (Papio anubis) and Wolf's monkeys (Cercopithecus wolfi) and unfamiliar birds, barnacle geese (Branta leucopsis). Primate male calls were loud calls and female calls were contact calls. All sounds were calls with a social positive valence (for the concerned species). For each of the eight biological stimuli, calls from five distinct individuals were used to prevent pseudo-replication. The term familiarity was used here as "common in the environment" and not in terms of "individual familiarity". Thus, the species-specific calls had been recorded from wild animals unknown to the experimental animals but they were considered as familiar in terms of "category of sounds commonly heard in the environment".

The sounds were broadcast at $75 \mathrm{~dB}$, as measured at $2 \mathrm{~m}$ (distance between the loudspeaker and the sitting tray). Each individual exemplar of sound was broadcast twice during the entire experiment: the whole series of sounds was broadcast (Session 1) before a second series of playback of the same sounds took place (Session 2). Each female therefore heard 90 sounds (5 exemplars of 8 biological 
sounds $\times 2+10$ times white noise). A total of 540 playbacks were thus performed. The order of playbacks of the stimuli was randomised for each session and a given female never heard the same succession of two stimuli, twice.

The analysis of the video recordings revealed head movements and orientations in response to playbacks that occurred within the second following the playback, that is before any group member in the other room could produce any vocal response [25]. Therefore, only changes in behaviour occurring in the second following playback were considered as responses. Changes in head orientation were only taken into account if the head movement was above $45^{\circ}$. Head orientation could be left, right or none.

\subsubsection{Statistical Analysis}

Non-parametric statistics were used: binomial tests to compare the number of responses/non-responses, the number of left/right responses for each and all stimuli, respectively; Wilcoxon test to compare right/left responses between sessions and stimuli and to ensure inter individual validity; and Spearman rank order correlation tests to test possible correlations between playback rendition order and response rate or orientation.

\subsection{Study 2: Electrophysiological Responses of Auditory Neurons to Different Sounds in European Starlings} (see also [38,93])

\subsubsection{Subjects}

In total, 26 wild-caught adult female European starlings were used for this study. These birds had been caught as adults in October $2006(\mathrm{~N}=10)$ or $2012(\mathrm{~N}=16)$ during their autumn migration along the Normandy coast (north of France), about 3 years before the beginning of the experiments They were then kept together with other males and females caught at the same time in an outdoor aviary with food and water ad libitum. Although seasonal changes occurred in these birds (e.g., beak colour change, see below), the absence of nest boxes prevented them from breeding. Thus, females were in an appropriate seasonal environment and they showed visible seasonal characteristics, such as beak colour changes, but they were not influenced by seasonal changes in male behaviour (song, sexual display, etc.). They were brought to the laboratory and temporarily housed in single cages, with close contact (visual and auditory) with the other neighbouring birds at the beginning of the experiments.

Ten females were recorded in an awake-restrained state: six outside the breeding season, in fall (November and December 2006) and four during the breeding season in spring (April 2006).

Sixteen other females (eight in fall 2014 and eight in spring 2015) were recorded while anaesthetised using a $4 \mathrm{~mL} / \mathrm{kg}$ mixture of $5 \mathrm{~mL}$ Medetomidine $(1 \mathrm{mg} / \mathrm{mL}), 0.25 \mathrm{~mL}$ Ketamine $(50 \mathrm{mg} / \mathrm{mL})$ and $5 \mathrm{~mL}$ saline solution. The recordings lasted about $6 \mathrm{~h}( \pm 10 \mathrm{~min})$ and, to maintain the anaesthesia level, we injected every $2 \mathrm{~h}$ a third of the first dose.

The physiological state of the birds was assessed by their bill colour; yellow during the breeding season, dark during the rest of the year. This characteristic is a very good indicator of gonadal activity [94-97]. All females tested in spring had a yellow beak, indicating that they were in breeding condition, and all females tested in autumn had a black beak, indicating that they were in a non-breeding state. Prior to the neurophysiological experiments, a stainless-steel well was implanted stereotaxically on the bird's skull under halothane anaesthesia $\left(0.4 \mathrm{~L} / \mathrm{min}\right.$ of carbogene- $95 \% \mathrm{O}_{2} / 5 \%$ $\mathrm{CO}_{2}$-saturated in halothane (2bromo2chloro1, 1, 1 trifluoroethane) and $0.6 \mathrm{~L} / \mathrm{min}$ of carbogene). The centre of the implant was located precisely with reference to the bifurcation of the sagittal sinus in the left hemisphere. This position allowed the implantation of the electrodes in both hemispheres. After surgery, the birds were allowed to rest for 3 days in individual cages. During this period, they could hear but not see each other. They were kept under natural photoperiod throughout the study. During the electrophysiological recordings, the well was used for fixation of the head and as the reference electrode. Before the first recording session, the bone was removed to allow electrode 
introduction in both hemispheres. The bone was slightly soaked with a drop of lidocaine (4\%) before removing it to avoid possible pain from the bone or the dura mater. This quantity of lidocaine was also sufficient to avoid pain during electrode insertion even if the electrode tip was too thin (diameter $<20 \mathrm{~lm}$ ) to stimulate the dura mater nociceptors. A piece of plastic foam was placed on the bird's head between each recording session in order to protect the brain surface.

The experiments were performed in France (licence No. 005283, issued by the Department of Veterinary Services of Ille-et-Vilaine) in accordance with the European Communities Council Directive of 24 November 1986 (86/609/EEC).

\subsubsection{Electrophysiological Recordings}

Before the neurophysiological experiments, a stainless-steel well was implanted stereotaxically on the bird's skull under isoflurane anaesthesia $\left(0.4 \mathrm{~L} / \mathrm{min}\right.$ of carbogene- $95 \% \mathrm{O}_{2}-5 \% \mathrm{CO}_{2}$-saturated in isoflurane and $0.6 \mathrm{~L} / \mathrm{min}$ of carbogene). The centre of the implant was located precisely with reference to the bifurcation of the sagittal sinus at $2.5 \mathrm{~mm}$ rostral and $1 \mathrm{~mm}$ in the left hemisphere. This position allowed the introduction of the electrodes in both hemispheres. After implantation, the birds were allowed to rest for three days in individual cages. During this period, they could hear but not see each other. They were kept under natural photoperiod throughout the study. During the electrophysiological recordings, the well was used for head fixation and as the electrode reference. Before the first recording session, the bone was removed to allow electrode introduction in both hemispheres.

All recordings were made using the same recording setup at a temperature of about $20^{\circ} \mathrm{C}$ and relative humidity of about $30 \%$. Neuronal activity was recorded systematically throughout Field L during the broadcast of every acoustic stimulus, using the same approach as [97].

A head holder was used to maintain the bird's head in a constant and stable position. We used an array of four microelectrodes (two in each hemisphere) made of tungsten wires insulated by epoxylite (FHC). Electrode impedance was in the range of 5-6 M 2 each. These electrodes spaced $1.2 \mathrm{~mm}$ apart in the sagittal plane and $2 \mathrm{~mm}$ apart in the coronal plane. Recordings were performed in one sagittal plane in each hemisphere. These planes were precisely located with reference to the bifurcation of the sagittal sinus: $2.5 \mathrm{~mm}$ rostral and $1 \mathrm{~mm}$ in each hemisphere. These coordinates ensured that recordings were made in Field L centred on the L2 sub-area described by Capsius et al. [98] and Cousillas et al. [99]. The artificial non-specific stimuli composed by pure tones and white noise allowed us to assess the presence of the tonotopic organisation that is characteristic of Field L and to confirm that recordings were done in this area $[99,100]$. Recordings in the left and right hemispheres were made simultaneously, at symmetrical locations. The recording planes were at the same location for all birds. Recordings were performed at 30-40 sites along the path of an electrode penetration. Three penetrations could be done during a $6 \mathrm{~h}$ session. Penetrations within one recording plane were $200 \mu \mathrm{m}$ apart. For each penetration, recordings started $600 \mu \mathrm{m}$ below the brain surface, at a site that gave no auditory response, and continued, every $200 \mu \mathrm{m}$, until no response was obtained in both outermost penetrations. The dimensions of the recording plane were $2.4 \mathrm{~mm}$ caudo-rostral and $3.6 \mathrm{~mm}$ dorso-ventral (8.64 mm 2 area).

\subsubsection{Auditory Stimuli}

Auditory stimuli consisted in artificial non-specific sounds and songs chosen for their behavioural relevance [101]: Class-I: species-specific whistles that are common to all males and are the bases for male-male interactions and dialectal variations; Class-II whistles that are more individual-specific but can be shared by close social (same sex) partners; and Class-III warbling motifs that are individual specific but can be shared by close social partners excepted for clicks, common in all male songs all year round and high-pitched trills that occur at the end of the warbling sequence and are more frequent at breeding time and especially in unmated males [102,103]. 
The stimulus set was made of these artificial non-specific sounds and exemplars of the three classes of songs (Figure 3). Although no adaptation was reported in the Field L using this kind of stimulus set [100], the stimuli were broadcast with intervals of at least $300 \mathrm{~ms}$ in order to avoid any problem of adaptation between the stimuli. The sequence of stimuli set was determined randomly and then the same sequence was repeated 10 times at each recording site.
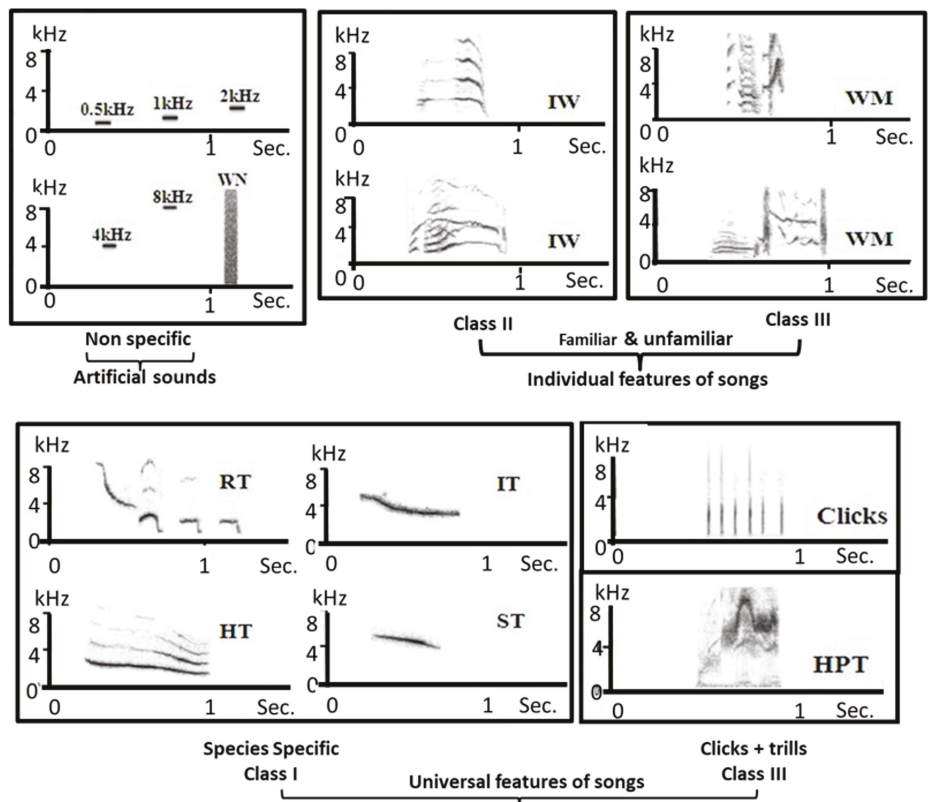

Figure 3. Stimulus set: artificial non-specific sounds and exemplars of Class I (species specific whistles), Class II (individual whistles) and Class III (individual warbling motifs and species specific clicks and trills)

Spike arrival times were obtained (with a temporal resolution of $0.1 \mathrm{~ms}$ ) by thresholding the extra-cellular recordings with a custom-made time- and level-window discriminator [97]. Single units or small multiunit clusters of 2-4 neurons were recorded in this manner. Since several studies found that analyses resulting from single and multi-units led to similar results $[104,105]$, the data from both types of units were analysed together.

The computer that delivered the stimuli also recorded the times of action potentials and displayed on-line rasters of the spike data for the four electrodes simultaneously. At each recording site, spontaneous activity was measured for $1.55 \mathrm{~s}$ before the presentation of the first stimulus of each sequence, which resulted in 10 samples of spontaneous activity (i.e., a total of $15.5 \mathrm{~s}$ ).

Neuronal responsiveness was assessed as in George et al. [23] by comparing activity level (number of action potentials) during stimulation and spontaneous activity using binomial tests. Only responsive sites were further analysed by calculating the proportion of sites responding to each stimulus and to each class of stimuli. The mean values calculated for individual birds were then used for statistical comparisons.

\subsubsection{Statistical Analyses}

Given the low number of subjects, non-parametric statistics were used to test for potential differences between the two hemispheres. 
Author Contributions: Conceptualisation, M.H., H.C., I.G. and C.B.-H.; Data curation, A.M., G.K. and I.G.; Formal analysis, M.H., A.M. and C.B.-H.; Funding acquisition, M.H.; Investigation, A.M. and C.B.-H.; Methodology, M.H., H.C., A.M. and C.B.-H.; Supervision, M.H. and C.B.-H.; and Writing-original draft, M.H., H.C., A.L. and C.B.-H.

Funding: This research received no external funding

Acknowledgments: We thank A. Rossard and P. Bec for taking care of the Paimpont primates, and D-M Paquet and S. Alcaix for electrophysiological recordings.

Conflicts of Interest: The authors declare no conflict of interest.

\section{References}

1. Broca, P. Remarques sur le siège de la faculté du langage articulé suivies d'une observation d'aphémie. Bull. Soc. Anat. 1861, 6, 398-407.

2. Rogers, L.J.; Andrew, R.J. Comparative Vertebrate Lateralization; Cambridge University Press: Cambridge, UK, 2002; ISBN 0-521-78161-2.

3. Mc Neilage, P.F.; Rogers, L.J.; Vallortigara, G. Origins of left and right Brain. Sci. Am. 2009, 301, 60-67. [CrossRef]

4. Vallortigara, G.; Chiandetti, C.; Sovrano, V.A. Brain asymmetry (animal). Adv. Rev. 2011, 2, 146-157. [CrossRef] [PubMed]

5. Rogers, L.; Vallortigara, G. When and why did brains break symmetry? Symmetry 2015, 7, 2181-2194. [CrossRef]

6. Taglialatela, J.P. Functional and structural asymmetries for auditory perception and vocal production in nonhuman primates. Spec. Top. Primatol. 2007, 5, 120-145.

7. Ocklenburg, S.; Ströckens, F.; Güntürkün, O. Lateralisation of conspecific vocalization in non-human vertebrates. Laterality 2013, 18, 1-31. [CrossRef]

8. George, I. Hemispheric asymmetry of songbirds. In The Two Halves of the Brain: Information Processing in the Cerebral Hemispheres; MIT Press Scholarship Online; Hugdahl, K., Westerhausen, R., Eds.; MIT Press: Cambridge, MA, USA, 2010; pp. 91-120. [CrossRef]

9. Konerding, W.S.; Zimmermann, E.; Bleich, E.; Hedrich, H.J.; Scheumann, M. The head turn paradigm to assess auditory laterality in cats: Influence of ear position and repeated sound presentation. PeerJ 2017, 5, e3925. [CrossRef]

10. Böye, M.; Güntürkün, O.; Vauclair, J. Right ear advantage for conspecific calls in adults and subadults, but not infants, California sea lions (Zalophus californianus): Hemispheric specialization for communication? Eur. J. Neurosci. 2005, 21, 1727-1732. [CrossRef]

11. Ehret, G. Left hemisphere advantage in the mouse brain for recognizing ultrasonic communications calls. Nature 1987, 325, 249-251. [CrossRef]

12. Palleroni, A.; Hauser, M. Experience-dependant plasticity for auditory processing in a raptor. Science 2003, 299, 1195. [CrossRef]

13. Siniscalchi, M.; Laddago, S.; Quaranta, A. Auditory lateralization of conspecific and heterospecific vocalizations in cats. Laterality 2016, 21, 215-227. [CrossRef] [PubMed]

14. Hauser, M.D.; Andersson, K. Left hemisphere dominance for processing vocalizations in adult, but no infant, rhesus monkeys: Field experiments. Proc. Natl. Acad. Sci. USA 1994, 91, 3946-3948. [CrossRef] [PubMed]

15. Hauser, M.D.; Agnetta, B.; Perez, C. Orienting asymmetries in rhesus monkeys: The effect on time-domain changes on acoustic perception. Anim. Behav. 1998, 56, 41-47. [CrossRef] [PubMed]

16. Szymanska, J.; Trojan, M.; Jakucinska, A.; Wejchert, K.; Kapusta, M.; Sikorska, J. Brain functional asymmetry of chimpanzees (Pan troglodytes): The example of auditory laterality. Pol. Psychol. Bull. 2017, 48, 87-92. [CrossRef]

17. Heffner, H.E.; Heffner, R.S. Temporal lobe lesions and perception of species-specific vocalizations by macaques. Science 1984, 236, 75-76. [CrossRef]

18. Heffner, H.E.; Heffner, R.S. Effect of unilateral and bilateral auditory cortex lesions on the discrimination of vocalizations by Japanese macaques. J. Neurophysiol. 1986, 56, 683-701. [CrossRef] [PubMed]

19. Okanoya, K.; Ikebuchi, M.; Uno, H.; Watanabe, S. Left-side dominance for song discrimination in Bengalese finches (Lonchura striata var. domestica). Anim. Cogn. 2001, 4, 241-245. [CrossRef]

20. Ghazanfar, A.A.; Smith-Rohrberg, D.; Hauser, M.D. The Role of Temporal Cues in Rhesus Monkey Vocal Recognition: Orienting Asymmetries to Reversed Calls. Brain Behav. Evol. 2001, 58, 163-172. [CrossRef] 
21. Cynx, J.; Williams, H.; Nottebohm, F. Hemispheric differences in avian song discrimination. Proc. Natl. Acad. Sci. USA 1992, 89, 1372-1375. [CrossRef]

22. George, I.; Vernier, B.; Richard, J.-P.; Hausberger, M.; Cousillas, H. Hemispheric specialization in the primary auditory area of awake and anesthetized starlings. Behav. Neurosci. 2004, 118, 597-610. [CrossRef]

23. George, I.; Cousillas, H.; Richard, J.-P.; Hausberger, M. State-dependent hemispheric specialization in the songbird brain. J. Comp. Neurol. 2005, 18, 48-60. [CrossRef] [PubMed]

24. Gil-da-Costa, R.; Hauser, M.D. Vervet monkeys and humans show brain asymmetries for processing conspecific vocalizations, but with opposite patterns of laterality. Proc. R. Soc. B 2006, 273, 2313-2318. [CrossRef] [PubMed]

25. Lemasson, A.; Koda, H.; Kato, A.; Oyakawa, C.; Blois-Heulin, C.; Masataka, N. Influence of sound specificity and familiarity on Japanese macaques' (Macaca fuscata) auditory laterality. Behav. Brain Res. 2010, 208, $286-289$. [CrossRef] [PubMed]

26. Arve, E.; Hugdahl, K. Attentional effect in dichotic listening. Brain and language 1995, 49, 189-201.

27. Locke, J.L.; Snow, C. Social influences on vocal learning in human and non-human primates. In Social Influences on Vocal Development; Snowdon, C.T., Hausberger, M., Eds.; Cambridge University Press: Cambridge, UK, 1997; pp. 274-292.

28. Watkins, J.A.S. Lateralization of Auditory Learning and Processing in the Domestic Chick (Gallus gallus domesticus). Ph.D. Thesis, University of Sussex, Sussex, UK, 1999.

29. Pohl, P. Central auditory processing. V: Ear advantages acoustic stimuli in Baboons. Brain Lang. 1983, 20, 44-53. [CrossRef]

30. Leliveld, L.M.C.; Scheumann, M.; Zimmermann, E. Effects of caller characteristics on auditory laterality in an early primate (Microcebus murinus). PLoS ONE 2010, 5, e9031. [CrossRef]

31. Basile, M.; Lemasson, A.; Blois-Heulin, C. Social and Emotional Values of Sounds Influence Human (Homo sapiens) and Non-human Primate (Cercopithecus campbelli) Auditory Laterality. PLoS ONE 2009, 4, e6295. [CrossRef]

32. Xue, F.; Fang, G.; Yang, P.; Zhao, E.; Brauth, S.E.; Tang, Y. The biological significance of acoustic stimuli determines ear preference in the music frog. J. Exp. Biol. 2015, 218, 740-747. [CrossRef]

33. Scheumann, M.; Zimmermann, E. Sex-specific asymmetries I communication sound perception are not related to hand preference in an early primate. BMC Biol. 2008, 6, 3. [CrossRef]

34. Reinholz-Trojan, A.; Włodarczyk, E.; Trojan, M.; Kulcz Nski, A.; Stefá Nska, J. Hemispheric specialization in domestic dogs Canis familiaris for processing different types of acoustic stimuli. Behav. Proc. 2012, 91, 202-205. [CrossRef]

35. Andrew, R.J.; Watkins, J.A.S. Evidence for cerebral lateralization from senses other than vision. In Comparative Vertebrate Lateralization; Rogers, L.J., Andrew, R.J., Eds.; Cambridge University Press: Cambridge, UK, 2002; pp. 365-382. ISBN 0-521-78161-2.

36. Chanvallon, S.; Blois-Heulin, C.; de Latour, P.R.; Lemasson, A. Spontaneous approaches of divers by free-ranging orcas (Orcinus orca): Age- and sex-differences in exploratory behaviours and visual laterality. Sci. Rep. 2017, 7, 10922. [CrossRef] [PubMed]

37. Vallortigara, G.; Rogers, L.J.; Bisazza, A. Possible evolutionary origins of cognitive brain lateralization. Brain Res. Rev. 1999, 30, 164-175. [CrossRef]

38. Karino, G.; George, I.; Loison, L.; Heyraud, C.; De Groof, G.; Hausberger, M.; Cousillas, H. Anesthesia and brain sensory processing: Impact on neuronal responses in a female songbird. Sci. Rep. 2016, 6, 39143. [CrossRef] [PubMed]

39. Rochais, C.; Sébilleau, M.; Menoret, M.; Oger, M.; Henry, S.; Hausberger, M.; Cousillas, H. Attentional state and brain processes: State-dependent lateralization of EEG profiles in horses. Sci. Rep. 2018, 8, 10153. [CrossRef] [PubMed]

40. De Groof, G.; Poirier, C.; George, I.; Hausberger, M.; Van der Linden, A. Functional changes between seasons in the male songbird auditory forebrain. Front. Behav. Neurosci. 2013, 7, 196. [CrossRef] [PubMed]

41. Lemasson, A.; Zuberbühler, K.; Hausberger, M. Socially meaningful vocal plasticity in Campbell's monkeys. J. Comp. Psychol. 2005, 119, 220-229. [CrossRef]

42. Lemasson, A.; Glas, L.; Barbu, S.; Lacroix, A.; Guilloux, M.; Remeuf, K.; Koda, H. Youngsters do not pay attention to conversational rules: Is this so for nonhuman primates? Sci. Rep. 2011, 1, 22. [CrossRef]

43. Hausberger, M.; Foraste, M.; Richard-Yris, M.-A.; Nygren, C. Differential response of female starlings to shared and nonshared song types. Etologia 1997, 5, 31-38. 
44. George, I.; Richard, J.-P.; Cousillas, H.; Hausberger, M. No need to Talk, I Know You: Familiarity Influences Early Multisensory Integration in a Songbird's Brain. Front. Behav. Neurosci. 2011, 4, 193. [CrossRef]

45. Hubel, D.H.; Henson, C.O.; Rupert, A.; Galambos, R. “Attention” Units in the Auditory Cortex. Science 1959, 129, 1279-1280. [CrossRef]

46. Henry, L.; Bourguet, C.; Coulon, M.; Aubry, C.; Hausberger, M. Sharing mates and nestboxes is associated with female 'friendship' in European starlings Sturnus vulgaris. J. Comp. Psychol. 2013, 157, 1-13. [CrossRef] [PubMed]

47. Lemasson, A.; Hausberger, M. Patterns of vocal sharing and social dynamics in a Campbell's monkeys. J. Comp. Psychol. 2004, 118, 347-359. [CrossRef] [PubMed]

48. Lemasson, A.; Blois-Heulin, C.; Jubin, R.; Hausberger, M. Female social relationships in a captive group of Campbell's monkeys (Cercopithecus campbelli campbelli). Am. J. Prim. 2006, 68, 1161-1170. [CrossRef] [PubMed]

49. Lemasson, A.; Boutin, A.; Boivin, S.; Blois-Heulin, C.; Hausberger, M. Horse (Equus caballus) whinnies: A source of social information. Anim. Cogn. 2009, 12, 693-704. [CrossRef]

50. Rogers, L.J. Evolution of hemispheric specialization: Advantages and disadvantages. Brain Lang. 2000, 73, 236-253. [CrossRef] [PubMed]

51. Hopkins, W.D.; Fernandez Carriba, S. Laterality of communicative behaviours in Non-human Primates: A critical analysis. In Comparative Vertebrate Lateralization; Rogers, L.J., Andrew, R.J., Eds.; Cambridge University Press: Cambridge, UK, 2002; pp. 445-479. ISBN 0-521-78161-2.

52. Ouattara, K.; Lemasson, A.; Zuberbühler, K. The alarm calls system of female Campbell's monkeys. Anim. Behav. 2009, 78, 35-44. [CrossRef]

53. Lemasson, A.; Gandon, E.; Hausberger, M. Attention to elders' voice in non-human primates. Biol. Lett. 2010. [CrossRef]

54. Basile, M.; Boivin, S.; Boutin, A.; Blois-Heulin, C.; Hausberger, M.; Lemasson, A. Socially dependent auditory laterality in domestic horses Equus caballus. Anim. Cogn. 2009, 12, 611-619. [CrossRef]

55. Hauber, M.E.; Cassey, P.; Woolley, S.M.; Theunissen, F.E. Neurophysiological response selectivity for conspecific songs over synthetic sounds in the auditory forebrain of non-singing female songbirds. J. Comp. Physiol. A 2007, 193, 765-774. [CrossRef]

56. Vallortigara, G.; Andrew, R.J. Laterality of response by chicks to change in a model partner. Anim. Behav. 1991, 41, 187-194. [CrossRef]

57. Deng, C.; Rogers, L.J. Social recognition and approach in the chick: Laterality and effect of visual experience. Anim. Behav. 2002, 63, 697-706. [CrossRef]

58. Zucca, P.; Sovrano, V.A. Animal lateralization and social recognition: Quails use their visual hemifield when approaching a companion and their right visual hemi-field when approaching a stranger. Cortex 2008, 44, 13-20. [CrossRef] [PubMed]

59. Peirce, J.W.; Leigh, A.E.; Kendrick, K.M. Configurational coding, familiarity and the right hemisphere advantage for face recognition in sheep. Neuropsychologia 2000, 38, 475-483. [CrossRef]

60. Siniscalchi, M.; Quaranta, A.; Rogers, L.J. Hemispheric specialization in dogs for processing different acoustic stimuli. PLoS ONE 2008, 3, e3349. [CrossRef] [PubMed]

61. Siniscalchi, M.; d'Ingeo, S.; Minunno, M.; Quaranta, A. Communication in dogs. Animals 2018, 8, 131. [CrossRef]

62. Baciadonna, L.; Nawroth, C.; Briefer, E.F.; McElligott, A.G. Perceptual lateralization of vocal stimuli in goats. Curr. Zool 2018, 3, 1-8. [CrossRef]

63. Lang, P.J.; Greenwald, M.K.; Bradley, M.M.; Hamm, A.O. Looking at pictures: Affective, facial, visceral, and behavioral reactions. Psychophysiology 1993, 30, 261-273. [CrossRef]

64. Andics, A.; Gácsi, M.; Faragó, T.; Kis, A.; Miklósi, A. Report voice-sensitive regions in the dog and human brain are revealed by comparative fMRI. Curr. Biol. 2014, 24, 574-578. [CrossRef]

65. Ratcliffe, V.F.; Reby, D. Orienting asymmetries in dogs' responses to different communicatory components of human speech. Curr. Biol. 2014, 24, 2908-2912. [CrossRef]

66. Andrew, R.J. The differential roles of right and left sides of the brain in memory formation. Behav. Brain Res. 1999, 98, 289-295. [CrossRef]

67. Vallortigara, G.; Andrew, R.J. Differential involvement of right and left hemisphere in individual recognition in the domestic chick. Behav. Proc. 1994, 33, 41-57. [CrossRef]

68. Austin, N.P.; Rogers, L.J. Asymmetry of flight and escape turning responses in horses. Laterality 2007, 12, 464-474. [CrossRef] [PubMed] 
69. Blois-Heulin, C.; Crevel, M.; Böye, M.; Lemasson, A. Visual laterality in dolphins: Importance of the familiarity of stimuli. BMC Neurosci. 2012, 13, 2-8. [CrossRef] [PubMed]

70. De Boyer Des Roches, A.; Richard-Yris, M.A.; Henry, S.; Ezzaouïab, M.; Hausberger, M. Laterality and emotions: Visual laterality in the domestic horse (Equus caballus) differs with objects' emotional value. Physiol. Behav. 2008, 94, 487-490. [CrossRef]

71. Larose, C.; Rogers, L.J.; Richard, M.A.; Hausberger, M. Laterality of horses associated with emotionality in novel situations. Laterality 2006, 11, 355-367. [CrossRef] [PubMed]

72. Smith, A.V.; Proops, L.; Grounds, K.; Wathan, J.; McComb, K. Functionally relevant responses to human facial expressions of emotion in the domestic horse (Equus caballus). Biol. Lett. 2016, 12, 20150907. [CrossRef]

73. Zimmerman, P.H.; Buijs, S.A.F.; Bolhuis, J.E.; Keeling, L.J. Behaviour of domestic fowl in anticipation of positive and negative stimuli. Anim. Behav. 2011, 81, 569-577. [CrossRef]

74. Davidson, R.J. Emotion and affective style: Hemispheric substrates. Psychol. Sci. 1992, 3, 39-43. [CrossRef]

75. Quaranta, A.; Siniscalchi, M.; Vallortigara, G. Asymetric tail-wagging responses by dogs to different emotive stimuli. Curr. Biol. 2007, 117, 199-201. [CrossRef]

76. Siniscalchi, M.; Lusito, R.; Vallortigara, G.; Quaranta, A. Seeing left- or right-asymmetric tail wagging produces different emotional responses in dogs. Curr. Biol. 2013, 23, 2279-2282. [CrossRef]

77. Armony, J.L.; Dolan, R.J. Modulation of spatial attention by fear-conditioned stimuli: An event-related fMRI study. Neuropsychologia 2002, 40, 817-826. [CrossRef]

78. Fox, E.; Russo, R.; Dutton, K. Attentional bias for threat: Evidence for delayed disengagement from emotional faces. Cogn. Emot. 2002, 16, 355-379. [CrossRef] [PubMed]

79. Smith, A.V.; Proops, L.; Grounds, K.; Wathan, J.; Scott, S.K.; McComb, K. Domestic horses (Equus caballus) discriminate between negative and positive human nonverbal vocalizations. Sci. Rep. 2018, 8, 13052. [CrossRef] [PubMed]

80. Welp, T.; Rushen, J.; Kramer, D.L.; Festa-Bianchet, M.; de Passillé, A.M.B. Vigilance as a measure of fear in dairy cattle. Appl. Anim. Behav. Sci. 2004, 87, 1-13. [CrossRef]

81. Balconi, M.; Vanutelli, M.E. Vocal and visual stimulation, congruence and lateralization affect brain oscillations in interspecies emotional positive and negative interactions. J. Soc. Neuro. 2016, 11, 297-310. [CrossRef]

82. Proops, L.; Mc Comb, K. Cross-modal individual recognition in domestic horses (Equus caballus) extends to familiar humans. Proc. R. Soc. B 2012, 279, 3131-3138. [CrossRef] [PubMed]

83. Karakas, S.; Erzengin, Ö.U.; Başar, E. A new strategy involving multiple cognitive paradigms demonstrates that ERP components are determined by the superposition of oscillatory responses. Clin. Neurophysiol. 2000, 111, 1719-1732. [CrossRef]

84. Syka, J.; Kuta, D.; Popelal, J. Responses to species-specific vocalizations in the auditory cortex of awake and anesthetized guinea pigs. Hear. Res. 2005, 206, 177-184. [CrossRef]

85. Huetz, C.; Philibert, B.; Edeline, J.M. A spike-timing code for discriminating conspecific vocalizations in the thalamocortical system of anesthetized and awake guinea pigs. J. Neurosci. 2009, 29, 334-350. [CrossRef]

86. Ishii, R.; Canuet, L.; Ishihara, T.; Aoki, Y.; Ikeda, S.; Hata, M.; Katsimichas, T.; Gunji, A.; Takahashi, H.; Nakahachi, T.; et al. Frontal midline theta rhythm and gamma power changes during focused attention on mental calculation: An MEG beam former analysis. Front. Hum. Neurosci. 2014, 8, 1-10. [CrossRef]

87. Andics, A.; Gábor, A.; Gácsi, M.; Faragó, T.; Szabó, D.; Miklósi, Á. Neural mechanisms for lexical processing in dogs. Science 2016, 353, 1030-1032. [CrossRef] [PubMed]

88. Bach, J.-P.; Lüpke, M.; Dziallas, P.; Wefstaedt, P.; Uppenkamp, S.; Seifert, H.; Nolte, I. Auditory functional magnetic resonance imaging in dogs-Normalization and group analysis and the processing of pitch in the canine auditory pathways. BMC Vet. Res. 2016, 12, 32. [CrossRef] [PubMed]

89. Borod, J.C.; Koff, E.; Caron, H.S. Right hemispheric specialization for the expression and appreciation of emotion; a focus on face. In Cognitive Processes in the Right Hemisphere; Perecman, E., Ed.; Academic Press: New York, NY, USA, 1983.

90. Tucker, D.M. Lateral brain function, emotion and conceptualization. Psychol. Bull. 1981, 89, 19-46. [CrossRef] [PubMed]

91. Siberman, E.K.; Weingarten, H. Hemispheric lateralization of function related to emotion. Brain Cogn. 1986, 5, 322-353. [CrossRef] 
92. Sackeim, H.; Gur, R.C. Lateral asymmetry in intensity of emotional expression. Neuropsychologia 1978, 16, 473-481. [CrossRef]

93. Cousillas, H.; George, I.; Alcaix, S.; Henry, L.; Richard, J.P.; Hausberger, M. Seasonal female brain plasticity in processing social vs. sexual vocal signals. Eur. J. Neurosci. 2013, 37, 728-734. [CrossRef] [PubMed]

94. Dawson, A. Plasma gonadal steroid levels in wild starlings (Sturnus vulgaris) during the annual cycle and in relation to the stages of breeding. Gen. Comp. Endocrinol. 1983, 49, 286-294. [CrossRef]

95. Ball, G.F.; Wingfield, J.C. Changes in plasma levels of luteinizing hormone and sex steroid hormones in relation to multiple-broodedness and nest-site density in male starlings. Physiol. Zool. 1987, 60, 191-199. [CrossRef]

96. De Ridder, E.; Pinxten, R.; Mees, V.; Eens, M. Short- and longterm effects of male-like concentrations of testosterone on female European starlings (Sturnus vulgaris). Auk 2002, 119, 487-497. [CrossRef]

97. George, I.; Cousillas, H.; Richard, J.-P.; Hausberger, M. A new extensive approach to single-unit responses using multisite recording electrodes: Application to the songbird brain. J. Neurosci. Methods 2003, 125, 65-71. [CrossRef]

98. Capsius, B.; Leppelsack, H.J. Response patterns and their relationship to frequency analysis in auditory forebrain centers of a songbird. Hear. Res. 1999, 136, 91-99. [CrossRef]

99. Cousillas, H.; Leppelsack, H.J.; Leppelsack, E.; Richard, J.P.; Mathelier, M.; Hausberger, M. Functional organization of the forebrain auditory centers of the European starling. A study based on natural sounds. Hear. Res. 2005, 207, 10-21. [CrossRef] [PubMed]

100. Leppelsack, H.J.; Vogt, M. Responses of auditory neurons in the forebrain of a songbird to stimulation with species-specific sounds. J. Comp. Physiol. 1976, 107, 263-274. [CrossRef]

101. Hausberger, M. Social influences on song acquisition and sharing in the European starling (Sturnus vulgaris). In Social Influences on Vocal Development; Snowdon, C.T., Hausberger, M., Eds.; Cambridge University Press: Cambridge, UK, 1997; pp. 128-156.

102. Verheyen, R.F. Breeding strategies of the starling. In Bird Problems in Agriculture; Wright, E.N., Inglis, I.R., Feare, C.J., Eds.; British Crop. Protection Council: Croydon, UK, 1980; pp. 69-82.

103. Henry, L.; Hausberger, M.; Jenkins, P.F. The use of song repertoire changes with pairing status in male European starling. Bioacoustics 1994, 5, 261-266. [CrossRef]

104. Amin, N.; Grace, J.A.; Theunissen, F.E. Neural response to bird's own song and tutor song in the zebra finch field L and caudal mesopallium. J. Comp. Physiol. 2004, 190, 469-489. [CrossRef]

105. Grace, J.A.; Amin, N.; Singh, N.C.; Theunissen, F.E. Selectivity for conspecific song in the zebra finch auditory forebrain. J. Neurophysiol. 2003, 89, 472-487. [CrossRef] [PubMed]

(C) 2019 by the authors. Licensee MDPI, Basel, Switzerland. This article is an open access article distributed under the terms and conditions of the Creative Commons Attribution (CC BY) license (http:/ / creativecommons.org/licenses/by/4.0/). 